\title{
Preparação de nanomateriais magnéticos baseados óxido de grafeno/quitosana, caracterização e sua aplicação na remoção de poluentes em águas.
}

\section{Tauany F. Neves*, Nicole B. Dalarme, Carolina S. F. Picone, Patrícia Prediger.}

\section{Resumo}

O intensivo e inadequado dos recursos hídricos, juntamente com os déficits no tratamento empregado aos mesmos, culminam na contaminação deste compartimento ambiental. Nesse contexto, a adaptação da nanotecnologia oferece uma oportunidade para a otimização tecnológica aplicada ao tratamento de águas e efluentes. Mediante essa perspectiva, o presente trabalho refere-se a síntese de compósitos magnéticos baseados óxido de grafeno/quitosana, sua elucidação estrutural e aplicação na remoção do corante marrom básico 4 em água.

\section{Palavras-chave:}

Nanomateriais, óxido de grafeno/quitosana, marrom básico 4.

\section{Introdução}

O óxido de grafeno (GO) (Figura 1a), resultado da oxidação incompleta do grafeno, pode interagir com compostos orgânicos por meio de coordenações e interações eletrostáticas. Ademais, o GO pode ter seu caráter adsorvente potencializado pela mistura deste material a outros compostos, dando origem aos chamados compósitos e pela inserção de novos grupos coordenantes ao mesmo. ${ }^{1}$ Deste modo, realizou-se a síntese de nanocompósitos magnéticos baseados GO/quitosana contendo unidades de sal de amônio quaternário (mCS/GO-QAS) (Figura 1b), sua elucidação estrutural e aplicação na remoção, via adsorção, do corante marrom básico 4 (BB4).

Figura 1. 1a) GO. 1b) mCS/GO-QAS.

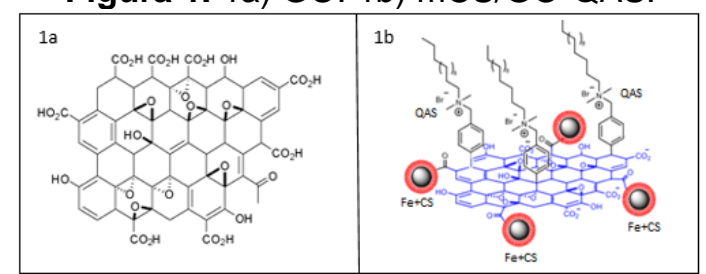

O corante (BB4) (Figura 2), trata-se de um composto neutro do grupo azo. Largamente empregado nas indústrias têxteis e de cosméticos, este, em meio aquoso é prejudicial a fauna e flora do ambiente e tóxico para o homem. ${ }^{2}$

Figura 2. 2a) BB4. 2b) BB4 em solução.

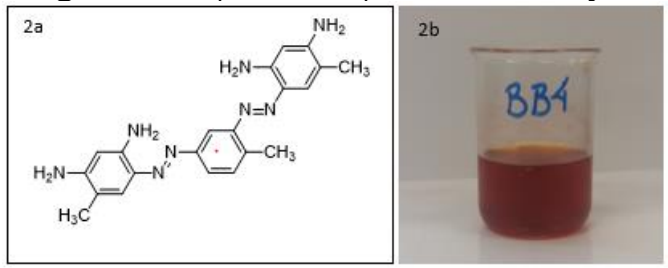

\section{Resultados e Discussão}

O mCS/GO-QAS foi preparado a partir da grafitização do sal de amônio quaternário ao $\mathrm{GO}$ e da posterior inserção das nanopartícula magnéticas de ferro aglutinadas na quitosana ao GO-QAS. Para sua caracterização, foram efetuadas diversas análises, destacando-se a espectroscopia no infravermelho com transformada de Fourier (FT-IR) e microscopia eletrônica de varredura (MEV) (Figura 3).

Figura 3. 3a) FT-IR. 2b) MEV.

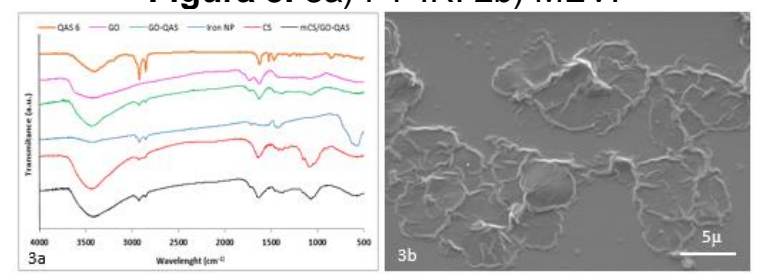

Após a caracterização do mCS/GO-QAS, variando-se parâmetros como tempo de contato, temperatura, $\mathrm{pH}$, concentração de nanomaterial e corante, foi realizada a otimização do processo de adsorção do BB4 ao material (Figura 4).

Figura 4. Resultados obtidos da otimização.

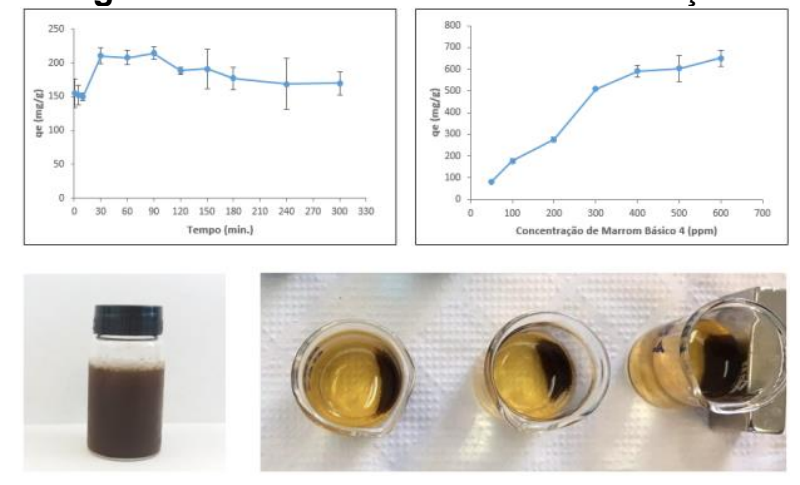

\section{Conclusões}

O mCS/GO-QAS foi sintetizado, caracterizado e aplicado no tratamento de água corada pelo corante BB4. Com uma capacidade de remoção de $650 \mathrm{mg} / \mathrm{g}$ obtida em um intervalo de tempo de 30 minutos, o material apresentou potencial de remoção superior a outros adsorventes.

\section{Agradecimentos}

Processo FAPESP 2018/10887-6; CNPEM; FAEPEX; CAPES; IQ; LAQOM; FT; PRG - UNICAMP.

${ }^{1}$ Wang, H. et al. J. Chem. Eng. Data. 2017, 62, 3341-3352.

${ }^{2}$ Manna, S. et al. Process Saf. Environ. Prot. 2017, 107, 346-356. 